\title{
Cognitive dysfunction in Major Depressive Disorder: Cause and effect.
}

Matthew J. Knight ${ }^{\text {a\# }}$, Natalie Aboustate ${ }^{\text {a\# }}$, Bernhard T. Baune ${ }^{\mathrm{b}}$

${ }^{a}$ Discipline of Psychiatry, Adelaide Medical School, University of Adelaide, Adelaide, Australia

${ }^{\mathrm{b}}$ Department of Psychiatry, Melbourne Medical School, The University of Melbourne, Melbourne, Australia

\# These authors contributed equally to this work and are considered first authors

${ }^{a}$ Matthew J. Knight

Adelaide Medical School

University of Adelaide

Health and Medical Sciences Building

North Terrace, Corner of George St

Adelaide, SA 5000

AUSTRALIA

Matthew.Knight@adelaide.edu.au

Ph: +61883136365

${ }^{\mathrm{b}}$ Corresponding author

Bernhard T. Baune

Department of Psychiatry

Melbourne Medical School

The University of Melbourne

Parkville, VIC 3010

Melbourne

AUSTRALIA

bbaune@unimelb.edu.au

Bernhard.Baune@adelaide.edu.au

Ph: +61-(0)3-8344-5509 


\section{Abstract}

\section{Purpose of Review}

Major depressive disorder (MDD) is a pervasive and debilitating mental illness, associated with significant emotional, social, and functional deficits. Growing evidence suggests that cognitive dysfunction is a core feature of MDD, and may negatively interact with other clinical features of the illness (e.g., psychosocial dysfunction, illness onset). We review recent advances in our understanding of cognitive dysfunction in MDD and highlight the putative causes and effects of cognitive deficits in depressed patients.

\section{Recent Findings}

Recent findings in this domain point to a multifaceted pathology of cognitive deficits in MDD, with behavioural disengagement and chronic low-grade inflammation likely playing an antecedent role. Emerging evidence suggests an independent role for cognitive deficits in the development of psychosocial dysfunction, particularly in domains of occupational function, interpersonal relationships and quality of life.

\section{Summary}

While the pathology of cognitive deficits in MDD is complex and multifaceted, recent advances provide clarity in select areas. Executive functioning stands out as a cognitive domain crucial to adaptive psychosocial status, highlighting the importance of remediating executive deficits with cognitive treatment. Low-grade inflammation may indicate a predisposition to severe, treatment-resistant depression and associated cognitive deficits. Screening for specific cognitive deficits and inflammatory markers in depressed patients may therefore prove crucial in the advancement of our detection and treatment of major depression.

\section{Keywords}

Major depression, MDD, Cognitive dysfunction, Inflammation, Executive function, Psychosocial functioning, 


\section{Introduction}

Major depressive disorder (MDD) is a major global health issue, affecting over 300 million individuals [1] and posing a great burden on both patients and clinicians [2,3]. While MDD is defined by chronic negative mood and lassitude, mounting evidence suggests that the illness is also characterised by impaired cognitive function. Recent reviews indicate that cognitive deficits in MDD are broad and span domains of executive functioning, working memory, attention, processing speed, and verbal fluency [4]. As such, cognitive performance in depressed patients is often observed 1-2 standard deviations below the norm [5]. Poor cognition has been linked to psychosocial dysfunction in domains of occupational functioning, daily autonomy, interpersonal relationships and self-perceived quality of life [6] . Cognitive deficits are also associated with illness chronicity, greater symptom severity, suicide, and illness relapse [3, 7]. In addition, several researchers have identified that cognitive dysfunction in MDD persists despite diagnostic remission, interfering with longitudinal functional recovery $[8,4]$. The broad impact of cognitive dysfunction in MDD highlights the need to elucidate its psychopathology and develop treatments tailored specifically to MDD patients who experience cognitive dysfunction $[9,10]$.

Historically, the causal role of cognition in the development of depressive symptoms has received considerable attention. For example, Beck's widely accepted cognitive model of depression places great emphasis on "hot" cognitive factors, which are defined as cognitive features influenced by emotional state (e.g., pessimistic bias) [11]. In Beck's model, depression is characterised by pervasive negative attitudes, systematic cognitive biases, and dysfunctional attitudes [12]. These factors negatively interact, resulting in loss of motivation, persistent negative mood, and contributing to both the onset and maintenance of depressive episodes. While Beck's cognitive model has been instrumental in shaping our understanding and treatment of depression over the past forty years, its predominance may have underemphasised the role "cold" cognitive features of MDD, defined as cognitive deficits which are not emotionally valenced (e.g., deficits in attention, executive function, memory). Deficits in patients' abilities to think, make decisions, and feel engaged (i.e., cold cognition) are included in DSM-5 criteria [13], however the development of cognitive deficits, as well as their interaction with other depressive symptoms, has only recently become a major research focus. 
There is a growing impetus to elucidate the pathology of cold cognitive deficits in MDD, which may be a barrier to long-term remission and functional recovery [14]. Understanding the causes of cognitive deficits will aid the development of treatments and preventative measures specifically targeting cognitive symptoms. Recent findings suggest that inflammation plays a key role in the pathophysiology of psychiatric disorders and cognitive dysfunction. However, the extent to which inflammatory markers influence specific cognitive domains, and their role in affecting specific brain regions associated with MDD remains contentious. The current review summarises recent advances in the field of cognition and MDD, including apparent behavioural and neuropsychiatric causes of cognitive dysfunction in depression, and the effect of cognitive deficits on social, psychosocial, and emotional features of MDD. Disentangling cognitive deficits from emotional symptoms and physiological perturbations is crucial to improve our ability to screening for and remediate these deficits [15].

\section{Behavioural causes of cognitive dysfunction in MDD}

Several behavioural features of depression may promote cognitive decline. For example, acute MDD is characterised by low mood, lassitude, and anhedonia, which significantly influence depressed patients' behaviour [16]. Losses in reward motivation and low energy lead to avoidance of cognitively stimulating behaviour, including exercise [17] hobbies [18] and employment [10]. Cognitive decline may follow as a consequence of limited opportunity to develop and reinforce cognitive faculties (e.g., problem solving, forward planning) and subsequently reduced activity-dependent neuroplasticity [19].

Recent research across a number of domains has supported the notion that behavioural factors contribute to cognitive dysfunction in MDD. For example, recent studies in occupational functioning have identified that depressed patients who are unemployed experience more severe cognitive deficits in immediate memory, delayed memory and visuospatial reasoning than depressed patients who are employed [20,21]. Reduced workplace productivity is also associated with self-perceived inattention [10], reinforcing the link between behavioural disengagement and cognitive dysfunction. A recent review by Greer, Furman and Trivedi also suggests lower rates of exercise are associated with poor cognition in depressed patients [22]. Mechanistically, lack of exercise may impair cognition due to its association with lower brain volume and greater neuronal atrophy [23]. Additionally, depressed patients typically experience greater social isolation (i.e., loneliness) than healthy individuals [16], where greater symptom severity is associated with higher rates of social isolation [24]. In turn, 
loneliness is longitudinally linked with cognitive decline in domains of immediate memory, working memory, perceptual speed, and visuospatial ability [25], suggesting social isolation plays a causal role in cognitive dysfunction. Sleep deprivation, a core symptom of depression [13], and is also associated with reduced neuroplasticity and brain function, particularly affecting cognitive functions centralised in the hippocampus including memory and learning [26]. Taken together, there is ample evidence that depression promotes occupational, social, and daily behaviour linked with cognitive decline.

\section{Bridging hot and cold cognition}

The dichotomy of hot and cold cognition was initially supported by neuroimaging studies that observed changes in blood flow [27] or neural activation [28] in specific regions of the brain during emotion-dependent or independent tasks. Imaging results suggested the lateral prefrontal cortex (PFC) was primarily responsible for cold cognition [29], whereas limbic regions were identified as regulators of emotion-laden cognitive function [30]. However, more recent studies have indicated that traditionally cold cognitive areas: dorsolateral PFC, inferior parietal lobule and dorsal cingulate, also control negative affect [31,32]. Further, in a model of emotional distraction, dorsolateral PFC activation increased participants' responses to both hot and cold stimuli during a working memory task, which improved performance with increasing task difficulty [33]. There is also evidence to support a more integrated hypothesis of cognitive functioning, where cross-talk between neural networks has culminated in the brain eliciting complex behaviours [34, 35]. For example, the lateral PFC stores information on an object's shape and location. Studies on primates have shown increased circuit firing in the PFC region during reward tasks (triggering 'hot' cognition), which consequently increased performance in visual tasks ('cold' cognitive function)[36]. Neuroimaging has also demonstrated cross-talk between hot and cold cognitive networks, including the dorsal salience network and medial amygdala [37, 34]. These findings suggest a close neurological overlap between hot and cold cognition, particularly with the elicitation of complex behaviours such as information evaluation and decision-making [38].

This overlap between hot and cold cognition is exemplified in individuals with MDD, who demonstrate a catastrophic response to failure during 'cold' cognitive testing[39], increasing their likelihood of error in subsequent test trials [40, 41]. MDD has also been associated with negatively biased information processing in attention, memory and reward schema[42]. As such, individuals with current and remittent MDD demonstrate hypersensitivity to negative valences in "emotion independent" tasks, being unable to separate negative information 
which is relevant to the task at hand [43, 28]. Neuroimaging implicates a hyperactive limbic axis and hypoactive PFC in the MDD brain when exposed to negatively-valanced stimuli compared to healthy controls $[44,45]$; a phenomenon partially ameliorated by anti-depressant use[46, 47]. It follows that MDD is associated with poor perception of emotional and nonemotional stimuli[48], which in turn interferes with information processing in cold cognitive tasks [28]. Further, positive stimuli are associated with a blunted activation in both the PFC and limbic system [49]. All together, these findings highlight the complex crossover between traditionally hot and cold cognitive domains in MDD, implicating dysfunctional emotional processing as an underlying cause of disrupted mood regulation.

\section{Inflammation-associated MDD and the ageing brain}

Physiological factors such as inflammation may also contribute to cognitive dysfunction in MDD [50]. Immune pathways are implicated in depressive behaviours and symptoms directly through damage to brain microstructures $[51,52]$ or indirectly through perturbations in neuroendocrine (HPA axis) [53] and neurotransmitter signalling [54, 55]. Cytokines present in the periphery are able to cross the blood brain barrier [56] and elicit 'sickness behaviours' such as lethargy, poor concentration, malaise and suppressed appetite [54]; all of which are common to MDD. While the effect of inflammation on cognitive functioning in MDD is yet to be fully characterised, dietary and aging studies suggest that environments with increased inflammation, oxidative stress, and older age are associated with cognitive decline[57, 58]. Studies of experimentally-induced inflammation through endotoxin administration demonstrate a positive correlation between IL6 expression and depressive mood symptoms [59], and pain-related cortical activation during social cognitive exercises [60]. Similarly, models of induced inflammation that administer typhoid vaccinations demonstrate temporary impairments in spatial memory in healthy individuals [61]. While these studies may be useful in determining the effects of acute inflammation, chronic low-grade inflammation (e.g. the ageing body) is a more common scenario frequently observed in MDD [62]. Recent evidence supports that peripheral chronic low-grade inflammation alters brain structure and promotes cognitive decline in MDD [63-65]. However, there is a lack specificity and understanding of the mechanistic pathways between inflammation and cognition [53], highlighting the need for more research in this area. Importantly, the relationship between inflammation and cognitive dysfunction is only observed in a subset of MDD patients [63], supporting the notion of a partial inflammatory mechanism for cognitive dysfunction. 
Cognition in the ageing brain is an interesting paradigm to consider as the elderly show increased circulation of inflammatory markers [66]. Further, cognitive decline is correlated with systemic markers of inflammation and compromised brain microstructures in ageing humans $[67,68]$. For example, diffusion anisotropy of the corpus callosum is reduced in elderly humans in association with poor cognition and increased systemic inflammation (independently of dementia) [69]. These elderly subjects also demonstrated decreased visuospatial ability in association with peripheral pro-inflammatory cytokine expression. As such, decreased microstructural integrity in the ageing corpus callosum (that regulates intellectual function) may confer secondary effects to fronto-parietal grey matter, which is necessary for visuospatial brain function. Longitudinal studies have also shown that increased expression of CRP and pro-inflammatory cytokines in peripheral blood are predictors of cognitive decline and increased risk of dementia later in life (for review see [58]). While inflammation causes neurodegeneration [70, 71], pharmacological anti-inflammatory interventions have not been effective in decreasing the risk of Alzheimer's disease [58]. Notably, most studies lack repeated measures of inflammation over time that could identify the effect of low-grade chronic inflammation on the brain. Such findings could inform suboptimal thresholds for the expression of inflammatory mediators and how they impact brain structure, neural activation and therefore cognitive function.

\section{Social, emotional, and psychosocial links with cognition}

A growing body of evidence suggests that cognitive dysfunction may cause social, emotional, and functional deficits in MDD [20, 72]. The negative influence of poor cognition on functional outcomes persists even after accounting for mood symptoms, indicating the unique contribution of cognition to psychosocial pathology [73, 14]. Poor executive functioning frequently stands out as the cognitive domain most strongly associated with functional disability [7, 74], possibly due to its role in behavioural and cognitive abilities crucial to adaptive psychosocial functioning (e.g., problem solving). The importance of executive functioning has been highlighted by clinical studies, which indicate that poor executive function partially mediates the negative effect of MDD on activities of daily living [75]. Interestingly, the relationship between executive subdomains and psychosocial dysfunction appears to differ between the acute and remitted stage of illness, with forward planning more primary in acute MDD and cognitive updating more primary in remitted MDD [74]. Given the broad effect of executive impairment on functional issues, clinicians should consider screening for executive dysfunction as a marker for psychosocial dysfunction more broadly 
[76], and clinical researchers should examine the efficacy of treatment programs designed to remediate executive deficits $[77,9]$. Current research on cognitive training suggests a broad positive effect on functional outcomes and mood symptoms [78], however transfer of cognitive benefit across cognitive domains is inconsistent, and there is very little clinical research available on the longitudinal maintenance of improvements following cognitive training [79].

While there is substantial evidence that cognitive deficits are associated with global psychosocial dysfunction, several areas of research in this domain remain unexplored. First, there is limited research exploring the domain specific relationships between cognitive and functional deficits (e.g., social relationships, daily autonomy) [7]. Existing research relies primarily on measures of overall cognition and or psychosocial function, which does not enable identification of specific treatment targets [80]. Emerging domain-specific research suggests that executive functioning is associated with deficits in occupational functioning and leisure time [74], and that poor attention, verbal memory, and processing speed are linked with reduced interpersonal relationships [81]. A second concern in this domain is the high reliance on self-reported and subjective measures of psychosocial dysfunction (e.g., Instrumental Activities of Daily Living; IADL)), as opposed to more objective measures (e.g., the Social Skills Performance Assessment; SSPA). Subjective scales of functioning may be more vulnerable to changes in patient mood symptoms and clinician bias, underscoring the need for more studies employing objective measures of psychosocial function (e.g., the Performance Assessment Skills Test; PASS).

Recent evidence suggests that cognitive deficits in MDD play a causal role in reduced social perception $[82,83]$, including reduced ability to detect and accurately interpret eye contact, prosody, body language, and infer the mental states of other people (i.e., theory of mind). Social perceptive deficits follow the trajectory of cold cognitive dysfunction, with social deficits more severe during the acute stage of MDD, and often persisting through remission [84]. The contribution of poor cognition to losses in social perception has been observed in other mental illnesses (e.g., Schizophrenia, Attention Deficit Hyperactivity Disorder) [85], though more research is needed to examine this link in MDD [86]. A potential causative role of cold-cognitive symptoms in poor social perception was identified by Joorman and Gotlib, who found that negative information consumes limited capacity working memory resources in depressed patients [87]. Given the significant cognitive load imposed on working memory in social interactions, it stands to reason that reduced availability of cognitive resources could 
negatively affect social abilities. While cognitive dysfunction likely plays a part, social perceptive deficits appear jointly caused by pessimistic emotional biases, demonstrated by reduced sensitivity to detect positive facial emotion [88], and heightened sensitivity to detect fear and anger [89]. The role of emotion symptoms is further highlighted by the finding that increased illness severity appears to exacerbate negative social perception [84]. More research is warranted to disentangle the causal roles of emotional and cognitive symptoms to poor social perception in MDD.

In addition to enhancing social perceptive deficits, poor cold cognition may contribute to the development of hot cognitive symptoms of MDD, including pessimism, confirmatory biases, and oversensitivity to negative feedback [90]. The role of cognitive deficits in the development of emotional symptoms may be partially explained by reduced ability to attend, remember, and critically appraise emotionally salient information [87, 4, 90]. Reductions in these skills may render depressed patients more vulnerable to negative interpretations and pessimistic outlooks. It follows that cognitive training (i.e., remediation) programs that target domains involved in emotion processing may lead to greater reductions in emotional symptoms [77]. From a biological perspective, cognitive training may work to stimulate shared brain networks between cognition and emotion (e.g., the dorsolateral PFC), hence facilitating improved executive function and reduced susceptibility to negative emotional biases (e.g., overly low self-appraisal) [90,77]. Given the persistence of cognitive symptoms during remission and their resistance to anti-depressants, cognitive training may emerge as a crucial adjunctive treatment to improve long term clinical outcomes in MDD $[9,91,76]$.

There is a strong association between cognitive dysfunction and vulnerability to adverse psychiatric outcomes [92], though, its aetiology remains complex. There are bidirectional effects between impaired cognition and MDD, as they both reinforce poor quality of life, ruminating thought processes [93] and decreased psychosocial functioning [94, 95]. As such, even individuals remitted from depressive symptoms demonstrate vulnerability to MDD relapse due to poor functional outcomes (e.g. work performance, psychosocial function) associated with cognitive dysfunction[20]. Studies on individuals with remitted MDD have demonstrated impaired performance on emotional tasks is a predictor for increased depressive symptoms, one year following testing; as mediated by increased rumination[93]. It is postulated that cognitive dysfunction predisposes these individuals to an inability to expel negative thought patterns, leading to the onset or relapse of MDD [93, 96]. Impaired cognition is also associated with treatment resistance in MDD, where SSRI non-responders 
demonstrate executive dysfunction, poor verbal fluency and working memory [97-99]. Cognitive impairment concomitant with geriatric depression also places individuals at higher risk of developing dementia[100, 101]. 'Problem-solving' therapies have therefore been employed in an effort to improve neuroplasticity in the treatment of geriatric depression and proven more effective than psychotherapy alone[102, 103]. All together, these findings reinforce the importance of treating cognitive dysfunction alongside depressive symptoms to support sustained, functional recovery from MDD.

\section{Conclusion:}

Available evidence suggests a range of behavioural and neurobiological mechanisms underpin cognitive dysfunction in MDD, including occupational and social disengagement and chronic low-grade inflammation. The broad effect of cognitive dysfunction underscores the need to screen for cognitive deficits in MDD, as they may contribute causally towards associated features of depression, including psychosocial dysfunction and illness chronicity. More research is needed to examine the clinical efficacy of targeting the antecedents of cognitive dysfunction in MDD with personalised treatment. In particular, cognitive treatments focussing on maintenance of social, emotional, and psychosocial functioning, and pharmaceutical treatments incorporating anti-inflammatory treatments, may bolster cognitive functioning and aid longitudinal recovery from depression. Future clinical trials should evaluate the efficacy of tailored cognitive and anti-inflammatory treatment, emphasising longitudinal and functional recovery as primary treatment outcomes. Given the complex and heterogeneous pathology of cognitive dysfunction in MDD, developing treatments should specifically target and personalise treatment around causes of decline most evident within individuals, as a "one-fits-all" approach is insufficient. Future research should also examine the longitudinal relationship between cognitive and psychosocial dysfunction in distinct cohorts of MDD patients (e.g., elderly, psychotic MDD, severely/treatment resistant depression), as current knowledge of these fields remains highly limited [6]. Such research should identify whether specific patients groups exhibit greater vulnerability to cognitive deficits, or are more receptive to targeted cognitive treatment. 


\section{Financial support and sponsorship}

The current work was supported by an unrestricted grant from the James and Diana Ramsay Foundation. The funding body had no impact on the design or the content of the research.

\section{Compliance with Ethics Standards}

\section{Conflicts of interest:}

BB received speaker/consultation fees from: AstraZeneca, Lundbeck, Pfizer, Takeda, Servier, Bristol Myers Squibb, Otsuka, and Janssen-Cilag. The remaining authors have no conflicts of interest to declare.

\section{Human and animal rights informed consent}

All reported studies/experiments with human or animal subjects performed by the authors have been previously published and complied with all applicable ethical standards (including the Helsinki declaration and its amendments, institutional/national research committee standards, and international/national/institutional guidelines). 


\section{References}

1. World Health Organisation. Depression and other common mental disorders. World Health Organisation, http://apps.who.int/iris/bitstream/10665/254610/1/WHO-MSD-MER-2017.2-eng.pdf. 2017. http://apps.who.int/iris/bitstream/10665/254610/1/WHO-MSD-MER-2017.2-eng.pdf. Accessed January, 20182018.

2. Whiteford HA, Degenhardt L, Rehm J, Baxter AJ, Ferrari AJ, Erskine HE et al. Global burden of disease attributable to mental and substance use disorders: findings from the Global Burden of Disease Study 2010. The Lancet. 2013;382(9904):1575-86.

3. Vigo $D$, Thornicroft $G$, Atun R. Estimating the true global burden of mental illness. The Lancet Psychiatry. 2016;3(2):171-8.

4. Rock PL, Roiser JP, Riedel WJ, Blackwell AD. Cognitive impairment in depression: a systematic review and meta-analysis. Psychol Med. 2014;44(10):2029-40. doi:10.1017/\$0033291713002535.

5. Bortolato B, F Carvalho A, S McIntyre R. Cognitive dysfunction in major depressive disorder: a state-of-the-art clinical review. CNS \& Neurological Disorders-Drug Targets (Formerly Current Drug Targets-CNS \& Neurological Disorders). 2014;13(10):1804-18.

6. Cambridge OR, Knight MJ, Mills N, Baune BT. The clinical relationship between cognitive impairment and psychosocial functioning in major depressive disorder: a systematic review. Psychiatry Research. 2018.

7. Evans VC, Iverson GL, Yatham LN, Lam RW. The relationship between neurocognitive and psychosocial functioning in major depressive disorder: a systematic review. J Clin Psychiatry. 2014;75(12):1359-70. doi:10.4088/JCP.13r08939.

8. Knight MJ, Air T, Baune BT. The role of cognitive impairment in psychosocial functioning in remitted depression. Journal of affective disorders. 2018;235:129-34.

9. Knight MJ, Baune BT. Psychosocial Dysfunction in Major Depressive Disorder-Rationale, Design, and Characteristics of the Cognitive and Emotional Recovery Training Program for Depression (CERTD). Frontiers in psychiatry. 2017;8:280.

10. McIntyre RS, Soczynska JZ, Woldeyohannes HO, Alsuwaidan MT, Cha DS, Carvalho AF et al. The impact of cognitive impairment on perceived workforce performance: results from the International Mood Disorders Collaborative Project. Compr Psychiatry. 2015;56:279-82.

doi:10.1016/j.comppsych.2014.08.051.

11. Robinson OJ, Roiser JP, Sahakian BJ. Hot and cold cognition in major depressive disorder. Cognitive Impairment in Major Depressive Disorder: Clinical Relevance, Biological Substrates, and Treatment Opportunities. 2016:69. 
12. Beck AT. The evolution of the cognitive model of depression and its neurobiological correlates. American Journal of Psychiatry. 2008;165(8):969-77.

13. American Psychiatric Association. Diagnostic and statistical manual of mental disorders (DSM$\left.5^{\circledR}\right)$. American Psychiatric Pub; 2013.

14. Baune BT, Renger L. Pharmacological and non-pharmacological interventions to improve cognitive dysfunction and functional ability in clinical depression--a systematic review. Psychiatry Res. 2014;219(1):25-50. doi:10.1016/j.psychres.2014.05.013.

15. McIntyre RS, Best MW, Bowie CR, Carmona NE, Cha DS, Lee Y et al. The THINC-Integrated Tool (THINC-it) Screening Assessment for Cognitive Dysfunction: Validation in Patients With Major Depressive Disorder. J Clin Psychiatry. 2017;78(7):873-81. doi:10.4088/JCP.16m11329.

16. Miller $\mathrm{AH}$, Raison $\mathrm{CL}$. The role of inflammation in depression: from evolutionary imperative to modern treatment target. Nature Reviews Immunology. 2016;16(1):22.

17. Chang Y-K, Labban J, Gapin J, Etnier JL. The effects of acute exercise on cognitive performance: a meta-analysis. Brain research. 2012;1453:87-101.

18. Leventhal AM, Chasson GS, Tapia E, Miller EK, Pettit JW. Measuring hedonic capacity in depression: a psychometric analysis of three anhedonia scales. Journal of clinical psychology. 2006;62(12):1545-58.

19. Pittenger C, Duman RS. Stress, depression, and neuroplasticity: a convergence of mechanisms. Neuropsychopharmacology. 2008;33(1):88.

20. Baune BT, Miller R, McAfoose J, Johnson M, Quirk F, Mitchell D. The role of cognitive impairment in general functioning in major depression. Psychiatry Res. 2010;176(2-3):183-9. doi:10.1016/j.psychres.2008.12.001.

21. Clark M, DiBenedetti D, Perez V. Cognitive dysfunction and work productivity in major depressive disorder. Expert review of pharmacoeconomics \& outcomes research. 2016;16(4):455-63.

22. Greer TL, Furman JL, Trivedi MH. Evaluation of the benefits of exercise on cognition in major depressive disorder. General hospital psychiatry. 2017.

23. Erickson KI, Voss MW, Prakash RS, Basak C, Szabo A, Chaddock L et al. Exercise training increases size of hippocampus and improves memory. Proceedings of the National Academy of Sciences. 2011;108(7):3017-22.

24. Luanaigh CÓ, Lawlor BA. Loneliness and the health of older people. International Journal of Geriatric Psychiatry: A journal of the psychiatry of late life and allied sciences. 2008;23(12):1213-21. 25. Cacioppo JT, Hawkley LC. Perceived social isolation and cognition. Trends in cognitive sciences. 2009;13(10):447-54.

26. Kreutzmann J, Havekes R, Abel T, Meerlo P. Sleep deprivation and hippocampal vulnerability: changes in neuronal plasticity, neurogenesis and cognitive function. Neuroscience. 2015;309:173-90. 27. Mayberg HS, Liotti M, Brannan SK, McGinnis S, Mahurin RK, Jerabek PA et al. Reciprocal limbiccortical function and negative mood: converging PET findings in depression and normal sadness. Am J Psychiatry. 1999;156(5):675-82. doi:10.1176/ajp.156.5.675.

28. Stange JP, Jenkins LM, Hamlat EJ, Bessette KL, DeIDonno SR, Kling LR et al. Disrupted engagement of networks supporting hot and cold cognition in remitted major depressive disorder. J Affect Disord. 2018;227:183-91. doi:10.1016/j.jad.2017.10.018.

29. Roiser JP, Sahakian BJ. Hot and cold cognition in depression. CNS Spectr. 2013;18(3):139-49. doi:10.1017/s1092852913000072.

30. Pessoa L. Precis on The Cognitive-Emotional Brain. Behav Brain Sci. 2015;38:e71. doi:10.1017/s0140525×14000120.

31. Langenecker SA, Dawson EL, Mickey BJ, Ransom MT, Walker SJ, Meyers KK et al., editors. Cognitive control and neuronal functioning biomarkers as predictors of treatment response in major depression. BIOLOGICAL PSYCHIATRY; 2014: ELSEVIER SCIENCE INC 360 PARK AVE SOUTH, NEW YORK, NY 10010-1710 USA. 
32. Ochsner KN, Silvers JA, Buhle JT. Functional imaging studies of emotion regulation: a synthetic review and evolving model of the cognitive control of emotion. Annals of the New York Academy of Sciences. 2012;1251(1):E1-E24.

33. Erk S, Kleczar A, Walter H. Valence-specific regulation effects in a working memory task with emotional context. Neuroimage. 2007;37(2):623-32. doi:10.1016/j.neuroimage.2007.05.006. 34. Shackman AJ, Salomons TV, Slagter HA, Fox AS, Winter JJ, Davidson RJ. The integration of negative affect, pain and cognitive control in the cingulate cortex. Nature Reviews Neuroscience. 2011;12(3):154-67.

35. Pessoa L. The cognitive-emotional amalgam. Behav Brain Sci. 2015;38:e91. doi:10.1017/s0140525×14001083.

36. Kobayashi S, Lauwereyns J, Koizumi M, Sakagami M, Hikosaka O. Influence of reward expectation on visuospatial processing in macaque lateral prefrontal cortex. Journal of neurophysiology. 2002;87(3):1488-98. doi:10.1152/jn.00472.2001.

37. Raz G, Touroutoglou A, Wilson-Mendenhall C, Gilam G, Lin T, Gonen T et al. Functional connectivity dynamics during film viewing reveal common networks for different emotional experiences. Cognitive, Affective, \& Behavioral Neuroscience. 2016;16(4):709-23.

38. Simon D, Stenstrom DM, Read SJ. The coherence effect: Blending cold and hot cognitions. J Pers Soc Psychol. 2015;109(3):369-94. doi:10.1037/pspa0000029.

39. Elliott R, Sahakian BJ, Herrod JJ, Robbins TW, Paykel ES. Abnormal response to negative feedback in unipolar depression: evidence for a diagnosis specific impairment. J Neurol Neurosurg Psychiatry. 1997;63(1):74-82.

40. Elliott R, Sahakian BJ, McKay AP, Herrod JJ, Robbins TW, Paykel ES. Neuropsychological impairments in unipolar depression: the influence of perceived failure on subsequent performance. Psychol Med. 1996;26(5):975-89.

41. Murphy FC, Michael A, Robbins TW, Sahakian BJ. Neuropsychological impairment in patients with major depressive disorder: the effects of feedback on task performance. Psychol Med.

2003;33(3):455-67.

42. Miskowiak KW, Carvalho AF. 'Hot' cognition in major depressive disorder: a systematic review. CNS Neurol Disord Drug Targets. 2014;13(10):1787-803.

43. Yoon KL, LeMoult J, Joormann J. Updating emotional content in working memory: a depressionspecific deficit? J Behav Ther Exp Psychiatry. 2014;45(3):368-74. doi:10.1016/j.jbtep.2014.03.004. 44. Surguladze S, Brammer MJ, Keedwell P, Giampietro V, Young AW, Travis MJ et al. A differential pattern of neural response toward sad versus happy facial expressions in major depressive disorder. Biol Psychiat. 2005;57(3):201-9. doi:https://doi.org/10.1016/j.biopsych.2004.10.028.

45. Siegle GJ, Thompson W, Carter CS, Steinhauer SR, Thase ME. Increased Amygdala and Decreased Dorsolateral Prefrontal BOLD Responses in Unipolar Depression: Related and Independent Features. Biol Psychiat. 2007;61(2):198-209. doi:https://doi.org/10.1016/j.biopsych.2006.05.048.

46. Fales CL, Barch DM, Rundle MM, Mintun MA, Mathews J, Snyder AZ et al. Antidepressant treatment normalizes hypoactivity in dorsolateral prefrontal cortex during emotional interference processing in major depression. J Affect Disord. 2009;112(1-3):206-11. doi:10.1016/j.jad.2008.04.027.

47. Fu CY, Williams SR, Cleare AJ, et al. Attenuation of the neural response to sad faces in major depressionby antidepressant treatment: A prospective, event-related functional magnetic resonance imagingstudy. Archives of General Psychiatry. 2004;61(9):877-89. doi:10.1001/archpsyc.61.9.877. 48. Disner SG, Beevers CG, Haigh EAP, Beck AT. Neural mechanisms of the cognitive model of depression. Nature Reviews Neuroscience. 2011;12:467. doi:10.1038/nrn3027.

49. Schaefer HS, Putnam KM, Benca RM, Davidson RJ. Event-related functional magnetic resonance imaging measures of neural activity to positive social stimuli in pre- and post-treatment depression. Biol Psychiatry. 2006;60(9):974-86. doi:10.1016/j.biopsych.2006.03.024. 
50. Fourrier C, Sampson E, Mills NT, Baune BT. Anti-inflammatory treatment of depression: study protocol for a randomised controlled trial of vortioxetine augmented with celecoxib or placebo. Trials. 2018; In Press.

51. Dowell NG, Cooper EA, Tibble J, Voon V, Critchley HD, Cercignani M et al. Acute Changes in Striatal Microstructure Predict the Development of Interferon-Alpha Induced Fatigue. Biol Psychiat. 2016;79(4):320-8. doi:10.1016/j.biopsych.2015.05.015.

52. Harrison JE, Lophaven S, Olsen CK. Which Cognitive Domains are Improved by Treatment with Vortioxetine? International Journal of Neuropsychopharmacology. 2016;19(10):pyw054-pyw. doi:10.1093/ijnp/pyw054.

53. Kraynak TE, Marsland AL, Wager TD, Gianaros PJ. Functional neuroanatomy of peripheral inflammatory physiology: A meta-analysis of human neuroimaging studies. Neuroscience $\&$ Biobehavioral Reviews. 2018.

54. Rosenblat JD, Brietzke E, Mansur RB, Maruschak NA, Lee Y, McIntyre RS. Inflammation as a neurobiological substrate of cognitive impairment in bipolar disorder: Evidence, pathophysiology and treatment implications. Journal of Affective Disorders. 2015;188:149-59.

doi:https://doi.org/10.1016/i.jad.2015.08.058.

55. Capuron L, Miller AH. Immune system to brain signaling: neuropsychopharmacological implications. Pharmacology \& therapeutics. 2011;130(2):226-38.

56. Blatteis CM, Bealer SL, Hunter WS, Llanos QJ, Ahokas RA, Mashburn TA, Jr. Suppression of fever after lesions of the anteroventral third ventricle in guinea pigs. Brain research bulletin. 1983;11(5):519-26.

57. Freeman LR, Haley-Zitlin V, Rosenberger DS, Granholm A-C. Damaging effects of a high-fat diet to the brain and cognition: a review of proposed mechanisms. Nutritional neuroscience.

2014;17(6):241-51.

58. Bettcher BM, Kramer JH. Longitudinal inflammation, cognitive decline, and Alzheimer's disease: a mini-review. Clin Pharmacol Ther. 2014;96(4):464-9. doi:10.1038/clpt.2014.147.

59. Reichenberg A, Yirmiya R, Schuld A, Kraus T, Haack M, Morag A et al. Cytokine-associated emotional and cognitive disturbances in humans. Archives of general psychiatry. 2001;58(5):445-52. 60. Eisenberger NI, Inagaki TK, Rameson LT, Mashal NM, Irwin MR. An fMRI study of cytokineinduced depressed mood and social pain: the role of sex differences. Neuroimage. 2009;47(3):88190.

61. Harrison NA. Brain structures implicated in inflammation-associated depression. InflammationAssociated Depression: Evidence, Mechanisms and Implications. Springer; 2016. p. 221-48.

62. Zalli A, Jovanova O, Hoogendijk W, Tiemeier H, Carvalho L. Low-grade inflammation predicts persistence of depressive symptoms. Psychopharmacology. 2016;233(9):1669-78.

63. McAfoose J, Baune B. Evidence for a cytokine model of cognitive function. Neuroscience \& Biobehavioral Reviews. 2009;33(3):355-66.

64. Bortolato B, Miskowiak KW, Köhler CA, Maes M, Fernandes BS, Berk M et al. Cognitive remission: a novel objective for the treatment of major depression? BMC medicine. 2016;14(1):9.

65. Krishnadas R, Cavanagh J. Depression: an inflammatory illness? J Neurol Neurosurg Psychiatry. 2012:jnnp-2011-301779.

66. Franceschi C, Bonafè M, Valensin S, Olivieri F, De Luca M, Ottaviani E et al. Inflamm-aging: an evolutionary perspective on immunosenescence. Annals of the New York Academy of Sciences. 2000;908(1):244-54.

67. Baune BT, Smith E, Reppermund S, Air T, Samaras K, Lux O et al. Inflammatory biomarkers predict depressive, but not anxiety symptoms during aging: the prospective Sydney Memory and Aging Study. Psychoneuroendocrinology. 2012;37(9):1521-30.

68. Mooijaart SP, Sattar N, Trompet S, Lucke J, Stott DJ, Ford I et al. Circulating interleukin-6 concentration and cognitive decline in old age: the PROSPER study. Journal of internal medicine. 2013;274(1):77-85. 
69. Arfanakis K, Fleischman DA, Grisot G, Barth CM, Varentsova A, Morris MC et al. Systemic inflammation in non-demented elderly human subjects: brain microstructure and cognition. PloS one. 2013;8(8):e73107.

70. Miralbell J, Soriano JJ, Spulber G, López-Cancio E, Arenillas JF, Bargalló N et al. Structural brain changes and cognition in relation to markers of vascular dysfunction. Neurobiology of Aging.

2012;33(5):1003. e9-. e17.

71. Wersching H, Duning T, Lohmann H, Mohammadi S, Stehling C, Fobker M et al. Serum C-reactive protein is linked to cerebral microstructural integrity and cognitive function. Neurology.

2010;74(13):1022-9.

72. McIntyre RS, Cha DS, Soczynska JK, Woldeyohannes HO, Gallaugher LA, Kudlow P et al. Cognitive deficits and functional outcomes in major depressive disorder: determinants, substrates, and treatment interventions. Depress Anxiety. 2013;30(6):515-27. doi:10.1002/da.22063.

73. McIntyre RS, Lee Y. Cognition in major depressive disorder: a 'Systemically Important Functional Index'(SIFI). Current opinion in psychiatry. 2016;29(1):48-55.

74. Knight MJ, Baune BT. Executive subdomains are differentially associated with psychosocial outcomes in Major Depressive Disorder. Frontiers in Psychiatry. 2018;9:309.

75. Kiosses DN, Alexopoulos GS. IADL Functions, Cognitive Deficits, and Severity of Depression: A

Preliminary Study. The American Journal of Geriatric Psychiatry. 2005;13(3):244-9.

doi:10.1097/00019442-200503000-00010.

76. McIntyre RS, Best MW, Bowie CR, Carmona NE, Cha DS, Lee Y et al. The THINC-Integrated Tool

(THINC-it) Screening Assessment for Cognitive Dysfunction: Validation in Patients With Major

Depressive Disorder. The Journal of clinical psychiatry. 2017;78(7):873.

77. Baune BT. Does training of cognitive functions help affective remediation? : SAGE Publications Sage UK: London, England; 2017.

78. Motter JN, Pimontel MA, Rindskopf D, Devanand DP, Doraiswamy PM, Sneed JR. Computerized cognitive training and functional recovery in major depressive disorder: A meta-analysis. Journal of affective disorders. 2016;189:184-91.

79. MacQueen GM, Memedovich KA. Cognitive dysfunction in major depression and bipolar disorder: A ssessment and treatment options. Psychiatry and clinical neurosciences. 2017;71(1):1827.

80. Caldirola D, Grassi M, Riva A, Daccò S, De Berardis D, Dal Santo B et al. Self-reported quality of life and clinician-rated functioning in mood and anxiety disorders: Relationships and neuropsychological correlates. Comprehensive Psychiatry. 2014;55(4):979-88.

doi:10.1016/j.comppsych.2013.12.007.

81. Cotrena C, Branco LD, Shansis FM, Fonseca RP. Executive function impairments in depression and bipolar disorder: association with functional impairment and quality of life. J Affect Disord.

2016;190:744-53. doi:10.1016/j.jad.2015.11.007.

82. Weightman MJ, Air TM, Baune BT. A review of the role of social cognition in major depressive disorder. Frontiers in psychiatry. 2014;5.

83. Knight MJ, Baune BT. Cognitive dysfunction in major depressive disorder. Current opinion in psychiatry. 2018;31(1):26-31.

84. Weightman MJ, Air TM, Baune BT. A review of the role of social cognition in major depressive disorder. Front Psychiatry. 2014;5:179. doi:10.3389/fpsyt.2014.00179.

85. Harvey PD, Penn D. Social cognition: the key factor predicting social outcome in people with schizophrenia? Psychiatry (Edgmont). 2010;7(2):41.

86. Knight MJ, Baune BT. Social cognitive abilities predict psychosocial dysfunction in major depressive disorder. Depression and anxiety. 2018:1-9. doi:https://doi.org/10.1002/da.22844.

87. Joormann J, Gotlib IH. Updating the contents of working memory in depression: Interference from irrelevant negative material. Journal of abnormal psychology. 2008;117(1):182.

88. LeMoult J, Joormann J, Sherdell L, Wright Y, Gotlib IH. Identification of emotional facial expressions following recovery from depression. Journal of Abnormal Psychology. 2009;118(4):828. 
89. Bhagwagar Z, Cowen PJ, Goodwin GM, Harmer CJ. Normalization of enhanced fear recognition by acute SSRI treatment in subjects with a previous history of depression. American Journal of Psychiatry. 2004;161(1):166-8.

90. Roiser JP, Elliott R, Sahakian BJ. Cognitive mechanisms of treatment in depression. Neuropsychopharmacology. 2012;37(1):117.

91. lacoviello BM, Wu G, Alvarez E, Huryk K, Collins KA, Murrough JW et al. Cognitive-emotional training as an intervention for major depressive disorder. Depress Anxiety. 2014;31(8):699-706. doi:10.1002/da.22266.

92. Cooney RE, Joormann J, Eugene F, Dennis EL, Gotlib IH. Neural correlates of rumination in depression. Cogn Affect Behav Neurosci. 2010;10(4):470-8. doi:10.3758/cabn.10.4.470.

93. Demeyer I, De Lissnyder E, Koster EH, De Raedt R. Rumination mediates the relationship between impaired cognitive control for emotional information and depressive symptoms: A prospective study in remitted depressed adults. Behav Res Ther. 2012;50(5):292-7. doi:10.1016/j.brat.2012.02.012.

94. Boss L, Kang DH, Branson S. Loneliness and cognitive function in the older adult: a systematic review. Int Psychogeriatr. 2015;27(4):541-53. doi:10.1017/s1041610214002749.

95. Riddle M, McQuoid DR, Potter GG, Steffens DC, Taylor WD. Disability but not social support predicts cognitive deterioration in late-life depression. International Psychogeriatrics.

2015;27(5):707-14.

96. Joormann J, Gotlib IH. Emotion regulation in depression: relation to cognitive inhibition. Cognition and Emotion. 2010;24(2):281-98.

97. Dunkin JJ, Leuchter AF, Cook IA, Kasl-Godley JE, Abrams M, Rosenberg-Thompson S. Executive dysfunction predicts nonresponse to fluoxetine in major depression. Journal of affective disorders. 2000;60(1):13-23.

98. Gorlyn M, Keilp JG, Grunebaum MF, Taylor BP, Oquendo MA, Bruder GE et al.

Neuropsychological characteristics as predictors of SSRI treatment response in depressed subjects. Journal of Neural Transmission. 2008;115(8):1213.

99. Kampf-Sherf O, Zlotogorski Z, Gilboa A, Speedie L, Lereya J, Rosca P et al. Neuropsychological functioning in major depression and responsiveness to selective serotonin reuptake inhibitors antidepressants. Journal of affective disorders. 2004;82(3):453-9.

100. Morimoto SS, Kanellopoulos D, Manning KJ, Alexopoulos GS. Diagnosis and treatment of depression and cognitive impairment in late life. Ann N Y Acad Sci. 2015;1345:36-46.

doi:10.1111/nyas.12669.

101. Alexopoulos GS, Meyers BS, Young RC, Mattis S, Kakuma T. The course of geriatric depression with "reversible dementia": a controlled study. Am J Psychiatry. 1993;150(11):1693-9.

doi:10.1176/ajp.150.11.1693.

102. Mulsant BH. Problem-solving therapy reduces disability more than supportive therapy in older adults with major depression and executive dysfunction. Evid Based Ment Health. 2011;14(3):77. doi:10.1136/ebmh.14.3.77.

103. Alexopoulos GS, Raue PJ, Kiosses DN, Mackin RS, Kanellopoulos D, McCulloch C et al. Problemsolving therapy and supportive therapy in older adults with major depression and executive dysfunction: effect on disability. Arch Gen Psychiatry. 2011;68(1):33-41.

doi:10.1001/archgenpsychiatry.2010.177. 


\section{University Library}

\section{- M M N E R VA A gateway to Melbourne's research publications}

Minerva Access is the Institutional Repository of The University of Melbourne

Author/s:

Knight, MJ;Aboustate, N;Baune, BT

Title:

Cognitive Dysfunction in Major Depressive Disorder: Cause and Effect

Date:

2018-12-01

Citation:

Knight, M. J., Aboustate, N. \& Baune, B. T. (2018). Cognitive Dysfunction in Major

Depressive Disorder: Cause and Effect. Current Behavioral Neuroscience Reports, 5 (4), pp.302-309. https://doi.org/10.1007/s40473-018-0160-y.

Persistent Link:

http://hdl.handle.net/11343/283207 